\title{
Experimental Measurement of Frozen and Partially Melted Water Droplet Impact Dynamics
}

\author{
Jose Palacios ${ }^{1}$ and Sihong Yan $^{2}$ \\ The Pennsylvania State University, University Park, PA, 16802 \\ Jason $\operatorname{Tan}^{3}$ \\ General Electric, Niskayuna, NY, 12309 \\ Richard E. Kreeger ${ }^{4}$ \\ National Aeronautics and Space Administration
}

\begin{abstract}
High-speed video of single frozen water droplets impacting a surface was acquired. The droplets diameter ranged from $0.4 \mathrm{~mm}$ to $0.9 \mathrm{~mm}$ and impacted at velocities ranging from $140 \mathrm{~m} / \mathrm{sec}$ to $309 \mathrm{~m} / \mathrm{sec}$. The techniques used to freeze the droplets and launch the particles against the surfaces is described in this paper. High-speed video was used to quantify the ice accretion area to the surface for varying impact angles $\left(30^{\circ}\right.$, $45^{\circ}, 6^{\circ}$ ), impacting velocities, and break-up angles. An oxygen /acetylene cross-flow flame used to ensure partial melting of the traveling frozen droplets is also discussed. A linear relationship between impact angle and ice accretion is identified for fully frozen particles. The slope of the relationship is affected by impact speed. Perpendicular impacts, i.e. $30^{\circ}$, exhibited small differences in ice accretion for varying velocities, while an increase of $60 \%$ in velocity from $161 \mathrm{~m} / \mathrm{sec}$ to $259 \mathrm{~m} / \mathrm{sec}$, provided an increase on ice accretion area of $96 \%$ at an impact angle of $60^{\circ}$. The increase accretion area highlights the importance of impact angle and velocity on the ice accretion process of ice crystals. It was experimentally observed that partial melting was not required for ice accretion at the tested velocities when high impact angles were used $\left(45\right.$ and $\left.60^{\circ}\right)$. Partially melted droplets doubled the ice accretion areas on the impacting surface when 0.0023 Joules were applied to the particle. The partially melted state of the droplets and a method to quantify the percentage increase in ice accretion area is also described in the paper.
\end{abstract}

\section{Introduction}

$\mathbf{J}_{\mathrm{c}}^{\mathrm{H}}$ ET engine power-loss and damage can occur when ice particles are ingested by the engine during flight. Commercial airplanes with jet engines flying at high altitudes and close to convective systems, typically in tropical regions, have encountered engine-icing conditions responsible for surge/stall, flameout and engine damage. Engine stall occurs when ice sheds into the compressor surging the engine, and then stalling it, causing the rotor speeds to decay, and reducing airflow while the combustor remains lit. Flameout has been related to ice shed events into the combustor where the flame is quenched. Any ice accretion or shedding inside the engine can promote engine power-loss or damage. Engine-icing events happen in glaciated/mixed-phase environments that contain high density of ice particles1. Large number of ice particles enter the engine accreting along its core passage. Engine core flow blockage or shedding of accreted ice into the combustors are the main causes of engine failure 1.

Extensive work by Struck et al. ${ }^{2,} 3^{4,5}$ has been conducted to visualize ice growth on engine icing representative environments and to understand scaling needs related to sea-level testing. Evaporative cooling due to lower wet-bulb temperature is enhanced at high altitudes 2 . It was hypothesized that wet-bulb temperature could be a critical parameter influencing engine ice accretion. Limited testing has been conducted to determine if reproducing ice accretion of crystals representative of high altitude flight is possible at sea-level. Currie et al. ${ }^{6}$ presented the first experimental results performed at a high altitude representative environments in 2013 (National Research Council of Canada high altitude chamber) in an attempt to develop altitude-scaling laws such that sea level testing can be conducted for engine certification. In his research, Currie experimentally demonstrated that wet-bulb temperature, which was identified as an important variable in earlier studies, had little influence on accretion growth beyond its effect on particle melting. It was also demonstrated that accretion growth rate is proportional to the total water

\footnotetext{
${ }^{1}$ Assistant Professor, Aerospace Engineering, 233 Hammond Bldg., and AIAA Member.

${ }^{2}$ Research Assistant, Aerospace Engineering, 233 Hammond Bldg., and AIAA Member.

${ }^{3}$ Mechanical Systems Engineer, Performance Laboratory, One Research Circle, KWD150E, and AIAA Member.

${ }^{4}$ Aerospace Engineer, NASA Glenn Research Center, Building 11 NASA Glenn, and AIAA Associate Fellow.
} 
content (TWC) of the cloud and specifically to the ratio of the total water to the liquid water content (LWC) in the cloud. Maximum ice accretion was quantified to occur when mentioned TWC/LWC ratio ranged between 10 and $25 \%$. Currie's experimental findings allow for the reproduction of engine-icing environments at sea level if the TWC/LWC ratio can be controlled.

Mason et al. ${ }^{7}$ experimentally demonstrated that ice impingement on warm, above freezing, engine surfaces could cool the surface to freezing temperatures and allow for ice formation of partially melted crystals. It is believed that the ice crystals are ingested in the engine fully glaciated, but the increase in temperature in the early stages of the compressor section partially melts the drops such that they contain water content, and therefore, accrete to engine surfaces. Mason developed a testing facility that injects ice particles into a warm airstream to then deliver those particles to a test article without excessive melting, allowing for ice accretion. The tests demonstrated that mixedphase conditions are needed to form ice on an engine surface.

In addition to engine icing scaling laws and experimental ice accretion reproduction research, efforts to characterize the atmospheric clouds responsible for engine icing8 is being conducted. Efforts to 1) measure the ice shapes and shedding events, 2) to quantify the effects on engine performance degradation due to ice accretion, and 3) to model such accretion 9,10 are also on-going.

In this paper, an experimental technique to measure the dynamics of frozen drop impingement, breakup, and accretion is presented. The icing conditions reproduced in this experimental study attempt to simulate the ice crystal interaction with the hot regions of the compressor, and surface of the stator in a generic jet engine. It is difficult to study these crystal-engine interactions in a real compressor due to the variability in the flow, crystal thermal effects, and short residence time involved. It is also recognized that laboratory experimental conditions cannot truly simulate the flow dynamics in a compressor. Efforts are concentrated on the key physical correlations between droplet percentage melt, impact and rebound mechanics, and accretion. These correlations are pre-requisite to the development of practical ice crystal aero-thermal models for the gas turbine applications.

The proposed technique follows testing approaches described by Guégan ${ }^{11}$ and Cheong ${ }^{12}$. Guégan et al. ${ }^{11}$, performed ice impact visualization of $6 \mathrm{~mm}$ diameter frozen drops, while the tests described in this paper focus on the upper median diameter range of ice crystals encountered by engines operating under ice crystal environments (400 to $900 \mu \mathrm{m}$ ). Guégan studied the dynamics of the post-impact fragment cloud. Many other properties of impact dynamics such as size distribution and ejection velocity of fragments has been discussed in prior literature $\mathrm{e}^{12,13,14}$, but mainly focusing on glass or granules and not partially melted ice. Cheong et al. ${ }^{12}$ have conducted research on size distribution of fragments due to impact velocity and angle of glass sphere. Arakawa et al. ${ }^{13}$ focused on the ejection of ice-ice impact and the extent of breakage. The impact dynamic of single frozen drops with diameter representative of engine icing conditions allows to further understand the physics involved in the process of ice accretion to engine compressors.

Particle size effects have a significant effect on the ice accretion process as it has been discussed by Knezevici et al. ${ }^{15,16}$. The percentage melting of an ice crystal is related to its size, since smaller particles $(50-100 \mu \mathrm{m}$ median volume diameter) require smaller residence time at a given temperature to partially melt as compared to a larger drops (larger than $200 \mu \mathrm{m}$ ). In the presented work, frozen droplets on the upper limit of the size crystals that could be encountered in the atmosphere were used $(400-900 \mu \mathrm{m})$. The selection of such large drops is guided by the need to handle the droplets while they are inserted in the pneumatic launcher. The ultimate goal is to study the dynamics of the droplets upon impact for varying impact velocities, angles and percentage melt. The oversizing of the droplets is compensated with additional partial melting capabilities introduced by the oxygen /acetylene cross-flow flame.

\section{Objectives}

To overcome the difficulties of reproducing compressor ice accretion due to ice crystal ingestion, an experimental technique to create single frozen droplets and consequent partial melting and impact to a surface was developed. The objectives of the research presented in this paper are: 1) to describe the experimental techniques used to provided partially melted frozen drops traveling at controllable speeds between 140 and $250 \mathrm{~m} / \mathrm{sec}$, 2) to obtain experimental high-speed video to analyze the frozen drop impact dynamics and ice accumulation, 3) to analyze the correlation between ice fracture dynamics, ice accretion, and melted state for varying impact angles and velocities.

\section{Experimental Configuration}

The testing rig described in this paper is needed to understand the fundamental icing physics involved in the engine-icing phenomenon. The proposed approach controls the initial droplet size, cross-flow heating that provides partial melting, and the droplet velocity. One key physical parameter enforced during the presented research is the 
use of a single mono-sized water droplet, which minimizes the variability in the test and reduces the difficulty in discerning fundamental physics when multiple droplet impacts are encountered. The creation of frozen water droplets relies on liquid nitrogen to freeze water droplets. The water droplets are released by a syringe into a liquid nitrogen bath. The drops freeze instantaneously as they contact the liquid nitrogen bath. The frozen droplets are removed from the nitrogen bath and placed inside a temperature controlled environment $\left(-20^{\circ} \mathrm{C}\right)$ for a minimum of 30 minutes. The droplets are allowed to reach the steady state temperature of the surrounding environment such that the temperature of the frozen droplet can be assumed.

A sabot bullet, shown in Figure 1, is used to carry a single frozen droplet at its tip, to then be launched out of a barrel. A schematic of the sabot stopper at the end of the barrel is shown in Figure 2. The frozen water droplets are launched by the compression created by a spring-plunger system released inside a cylinder. The compressed air pushes the sabot until it hits the stopper. The stopper deforms the sabot, as depicted in Figure 2, but allows the frozen ice droplet to be launched towards the impact surface. At the exit of the barrel, where the droplet is launched, heated cross-flow introduces partial melting of the frozen drop. A schematic of the cross-flow heating units is shown in Figure 3. The two heating units seen in the photographs shown in Figure 4 introduce a cross-flow of $906 \mathrm{~L} / \mathrm{min}$, (32 CFM), at an average temperature of $160^{\circ} \mathrm{C}$. The residence time of the frozen drop varies between $50 \mu \mathrm{sec}$ seconds when the drop travels at $250 \mathrm{~m} / \mathrm{sec}$. To promote partial melting, increasing the temperature provided by the 2,800 Watts heated cross-flow was required. A third source of cross-flow heating was introduced: a $1.2 \mathrm{~cm}$ diameter oxygen /acetylene flame.

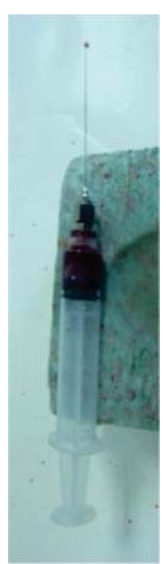

Figure 1. Photographs of syringe to create $500 \mu \mathrm{m}$ water drops, 3,000 $\mu \mathrm{m}$ water drops frozen in LN2 and frozen droplet placed into sabot bullet.

The drop impacted aluminum surfaces at varying impact angles $\left(30^{\circ}, 45^{\circ}\right.$ and $\left.60^{\circ}\right)$, velocities $(140$ to $309 \mathrm{~m} / \mathrm{sec})$ and melted conditions controlled by cross-flow temperature. Two high-speed cameras recorded the impact for two planes of view, such that impact velocity and ice accretion area could be acquired. High-speed video frames are used to measure the effects of particle break-up trajectory with impact angle, velocity, and partial melted state of the frozen droplet. The ice accumulation created by frozen drops and partially melted drops was also measured from the images. The cameras used were two Phantom M310. The cameras were set-up such that 50,000 fps could be obtained at a screen resolution of $128 \times 304$ pixels with an exposure time of $2 \mu \mathrm{sec}$. Two Micro Nikkor lenses were used. A $200 \mathrm{~mm} \mathrm{f} 4.0$ lens was used on the side view camera, while a $60 \mathrm{~mm}$ lens was used on the front view camera. A schematic of the camera placements is shown in Figure 5.

The camera system was operated from the control room by means of an Ethernet cable. The camera was connected to a triggering software that allowed for precise timing of capture from each impact event with respect to the particle release. Shadow-graph lighting to the area in which the impacts were going to take place was accomplished with an ArriSun 575 watt HMI light source for the side view. The front view used a 6,000 lumens LED system placed around the lens of the camera. The light was reflected by surface of the aluminum wedge.

The velocity control of the droplets is obtained by increasing the number of sabot bullets used in the configuration. A single bullet provided averaged velocities of $259 \mathrm{~m} / \mathrm{sec}$, while two stacked bullets decrease the velocity to an average of $161 \mathrm{~m} / \mathrm{sec}$. 


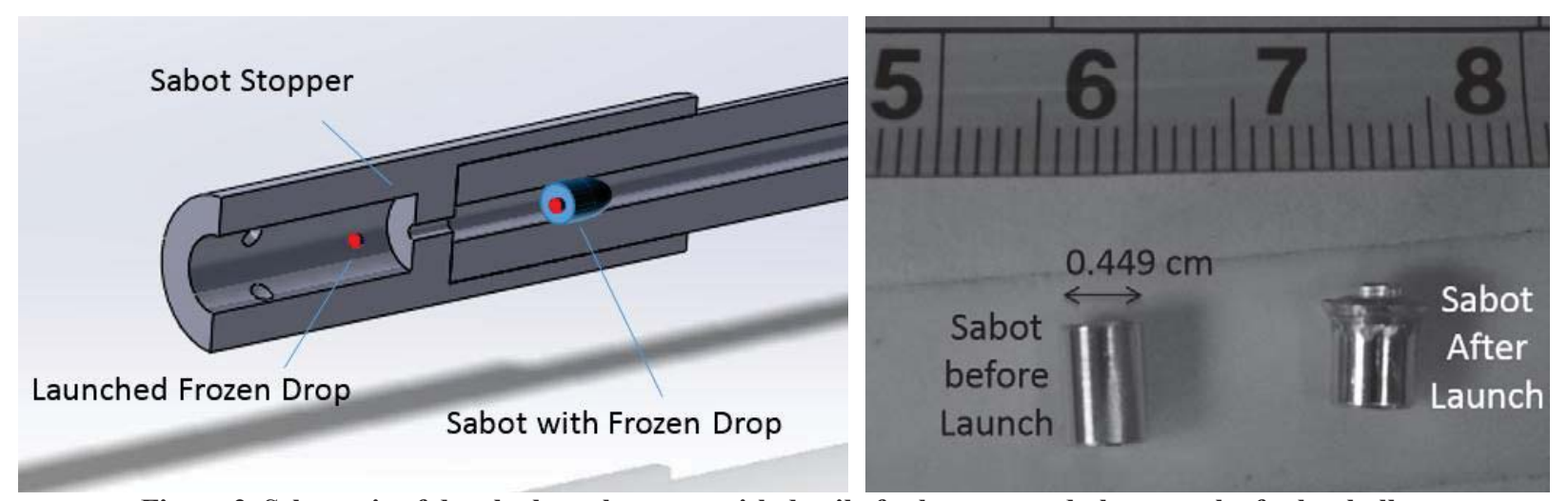

Figure 2. Schematic of droplet launch output with detail of sabot stop and photograph of sabot bullet.
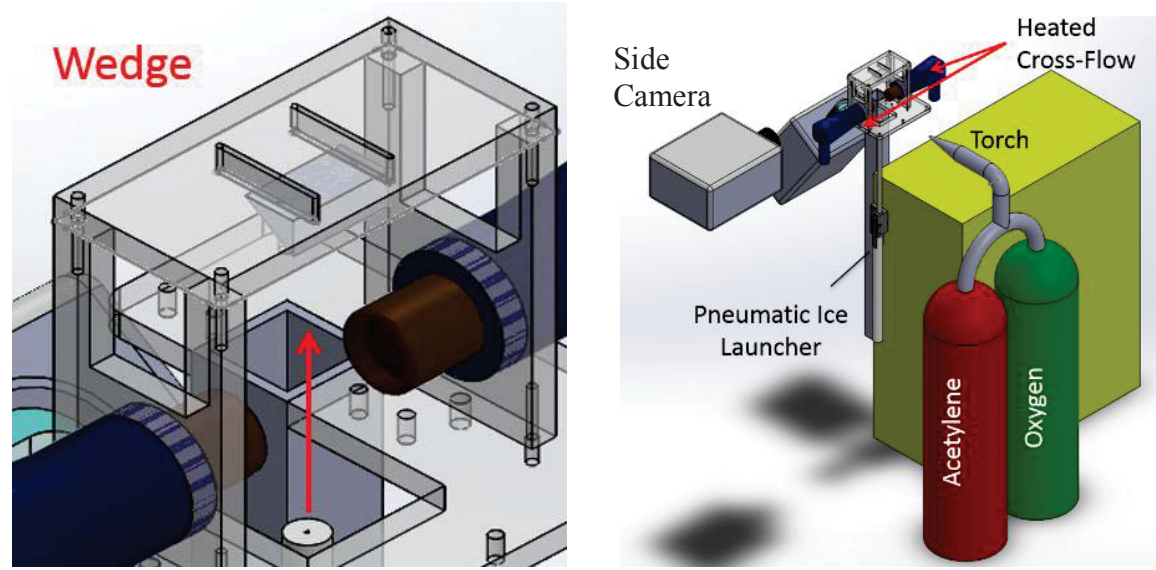

Figure 3. Schematic of experimental configuration.

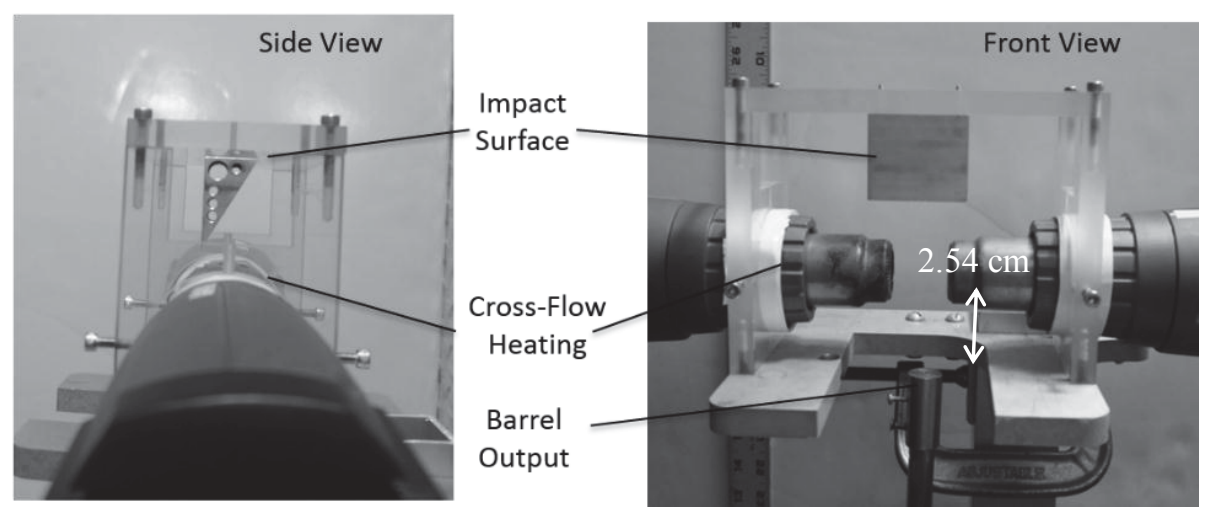

Figure 4. Photograph of side view and front view of the impact surface.

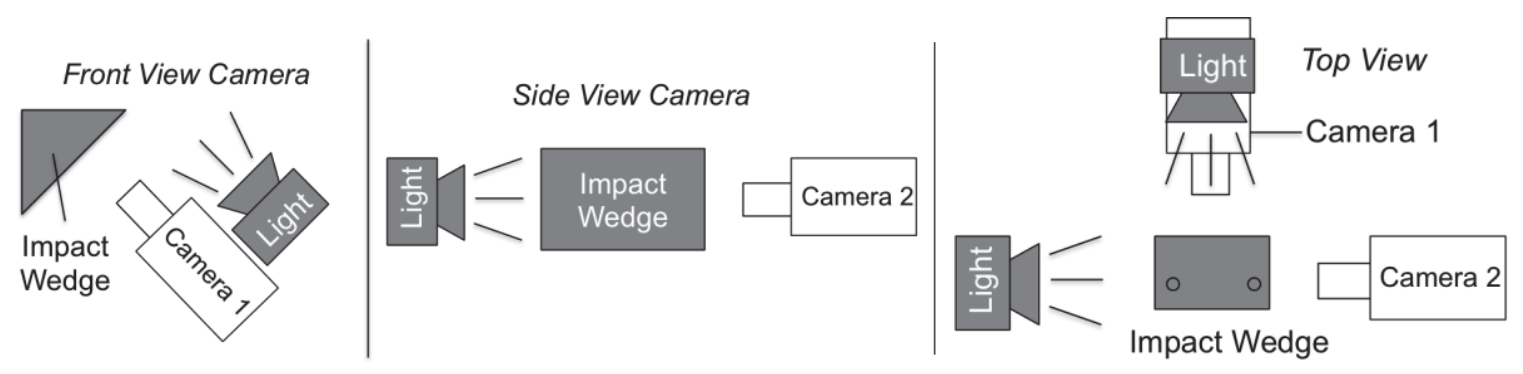

Figure 5. Schematic of camera placement.

American Institute of Aeronautics and Astronautics 


\section{Ice Accretion Quantification Parameter}

The frozen drops launched against the impact surfaces varied from 0.4 to $0.9 \mathrm{~mm}$, averaging $0.65 \mathrm{~mm}$. Given the variation in droplet size used during testing, and to allow for the comparison of the accretion area for varying cases, a ratio of the ice accretion area and the impacting droplet projection area is defined. Equation 1 defines mentioned area ratio.

$$
A R=\frac{\text { Ice Accretion Area }}{\text { Droplet Projection Area }}
$$

The projection area of the incoming water droplet and the ice accretion area are measured from images captured by the high-speed video. The high-speed video is also used to quantify the incoming particle velocity from the side view, as well as the post-impact particle break-up angle and front velocity. A sample of the data processing conducted to convert the raw frames to binary data for processing is shown in Figure 6.

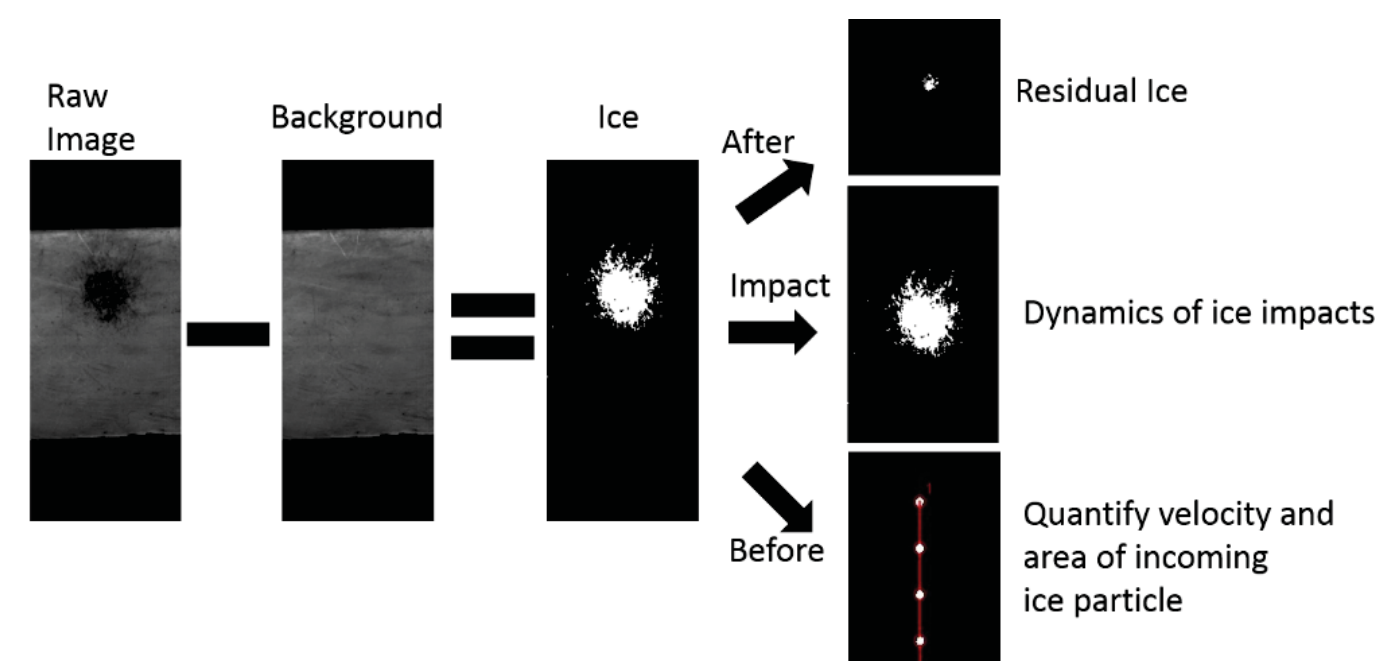

Figure 6. Example of background subtraction for conversion to binary of high-speed frames.

\section{Ice Fracture Dynamics and Accretion Results}

\section{A. Test Matrix}

Twenty-six tests were conducted, varying the impact speed, wedge angle, and cross-flow temperature. For all the cases the wedge temperature, impact velocity, droplet diameter, and ice accretion area were measured. All the cases were conducted at a room temperature of $-20^{\circ} \mathrm{C}$. The majority of the test cases were conducted with a high-speed camera frame acquisition of 50,000 fps, excepting cases $21,22,23$, when a frame rate of 20,000 was used. It is important to mention that the heating cross-flow affected the temperature of the wedges. The largest ice accretion occurred when the partial melting of the traveling frozen drop was maximum. For these conditions, the surface of the wedge was quantify to be as high as $8.79^{\circ} \mathrm{C}$. Also, notice that the area ratio is calculated from the measured area of the projection of the droplet seeing in the side view and the ice accretion area captured by the front view visualization.

As mentioned in prior sections, due to the large size of the particles used, the cross-flow heating provided by the heat guns was not sufficient to provide partial melting. All the values obtained with the heat guns were averaged with those values that did not provide cross-flow heating, since the heat guns did not provide partial melting. The standard deviation of the area ratio between the results obtained at $30^{\circ}$ impact angles was quantified to be 0.035 , while a standard deviation of 1.25 was obtained for the $60^{\circ}$ cases. 


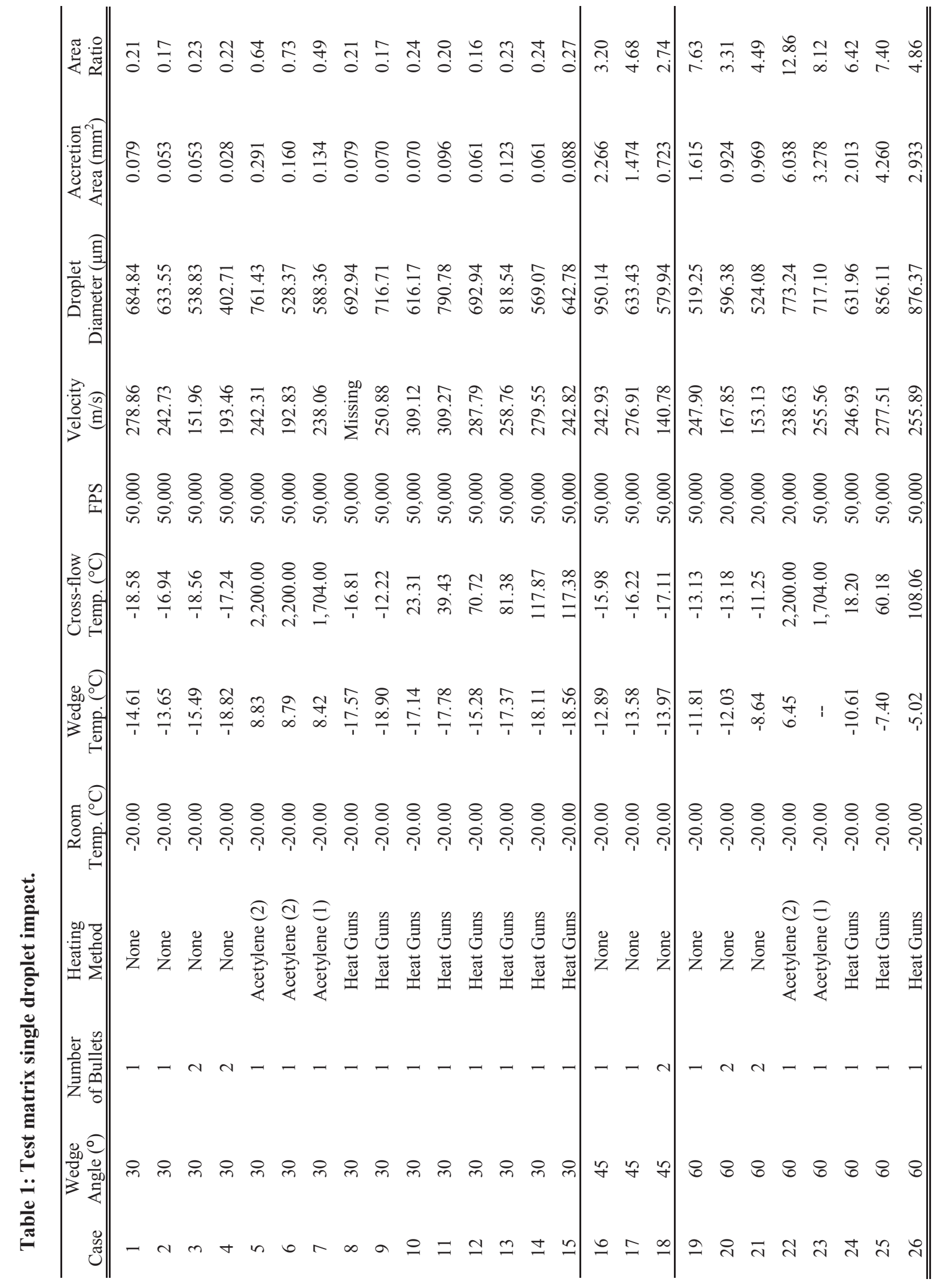




\section{B. Fracture Correlation between Varying Impact Angle and Velocity}

The quantified ice accretion/droplet projection area ratio, $A R$, for varying wedge angles and impact velocity is shown in Figure 7. A rise in ice accretion area is measured as impact velocity is increased from $161 \mathrm{~m} / \mathrm{sec}$ to 259 $\mathrm{m} / \mathrm{sec}$. An increase in the ice accretion is also quantified for increased impact angles. The increase of ice accretion area follows a linear trend for varying impact angles, especially for the higher velocity case as shown in Figure 7. As mentioned in prior sections, impact velocities surrounding $250 \mathrm{~m} / \mathrm{sec}$ (averaging $259 \mathrm{~m} / \mathrm{sec}$ ) were reproducible within a standard deviation of $18.4 \mathrm{~m} / \mathrm{sec}$, while velocities in the range of $150 \mathrm{~m} / \mathrm{sec}$ (averaging $161 \mathrm{~m} / \mathrm{sec}$ ) had a standard deviation of $20.3 \mathrm{~m} / \mathrm{sec}$, explaining the higher linearity of the experimental results related to the former velocity condition. The $\mathrm{R}^{2}$ value for the linear fit for the averaged cases tested at $259 \mathrm{~m} / \mathrm{sec}$ is 0.999 while the $\mathrm{R}^{2}$ value for those cases obtained at $161 \mathrm{~m} / \mathrm{sec}$ is 0.967 . The $60 \%$ increase in velocity from $161 \mathrm{~m} / \mathrm{sec}$ to $259 \mathrm{~m} / \mathrm{sec}$ provided an increase on ice accretion area ratio of $96 \%$ at an impact angle of $60^{\circ}$. For more perpendicular impacts, i.e. $30^{\circ}$, the effects of impact velocity increases on ice accretion area is minimal.

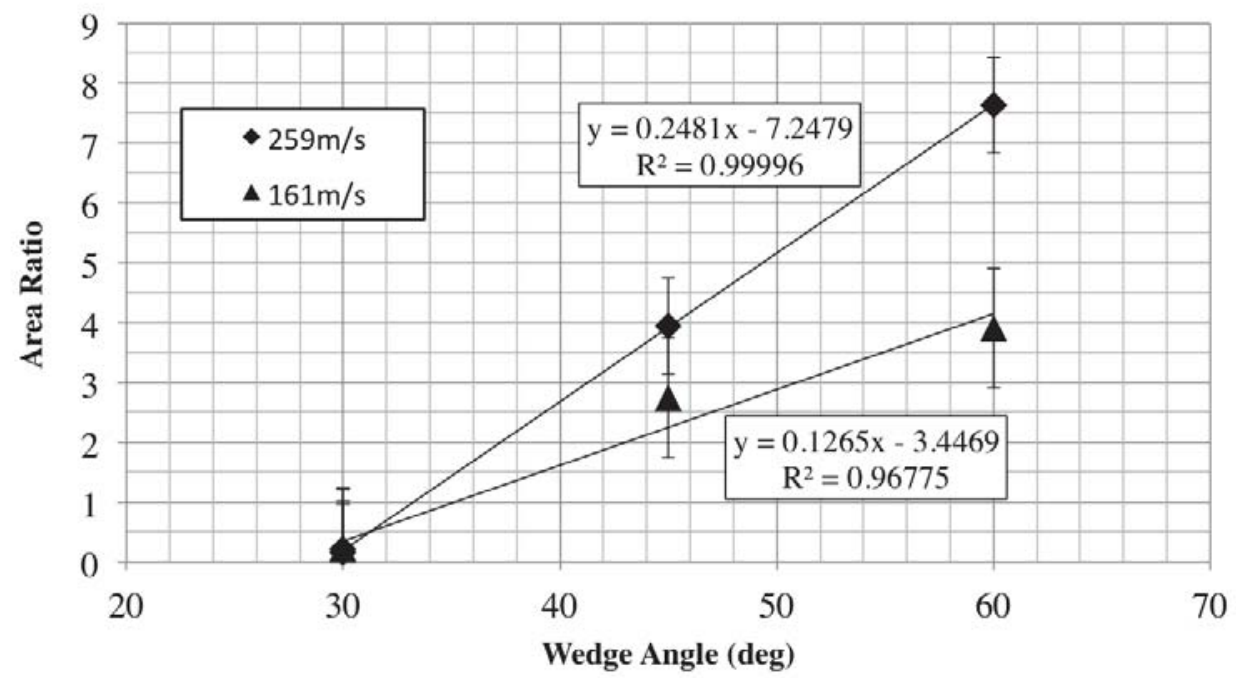

Figure 7. Ice accretion area ratio for varying wedge angles and impact velocities.
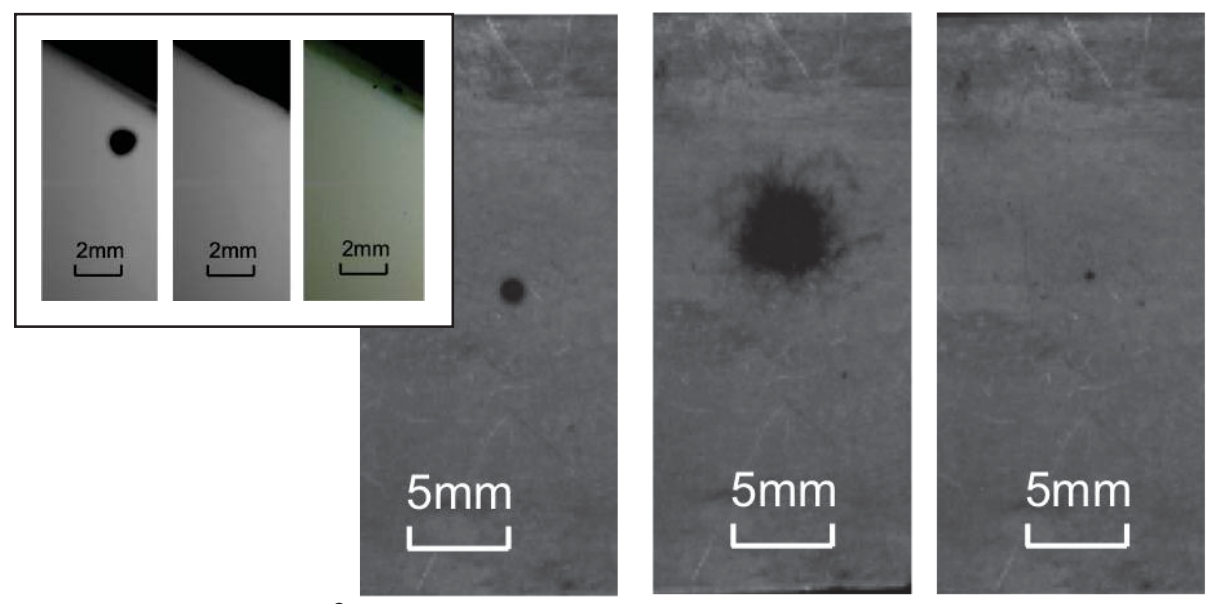

Figure $8.30^{\circ}$ wedge frozen drop impact frames and ice accumulation (Front and side view). 


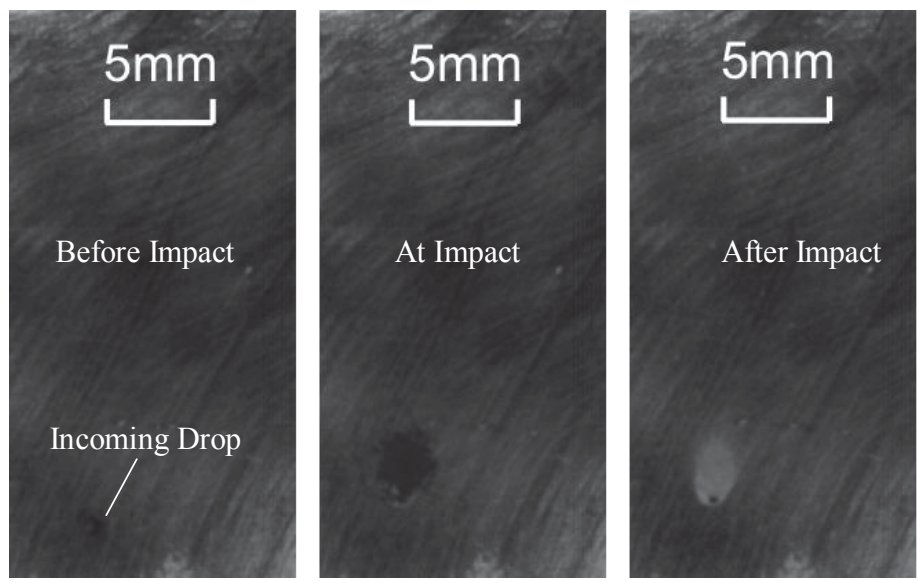

Figure $9.45^{\circ}$ wedge frozen drop impact frames and ice accumulation (Front view).

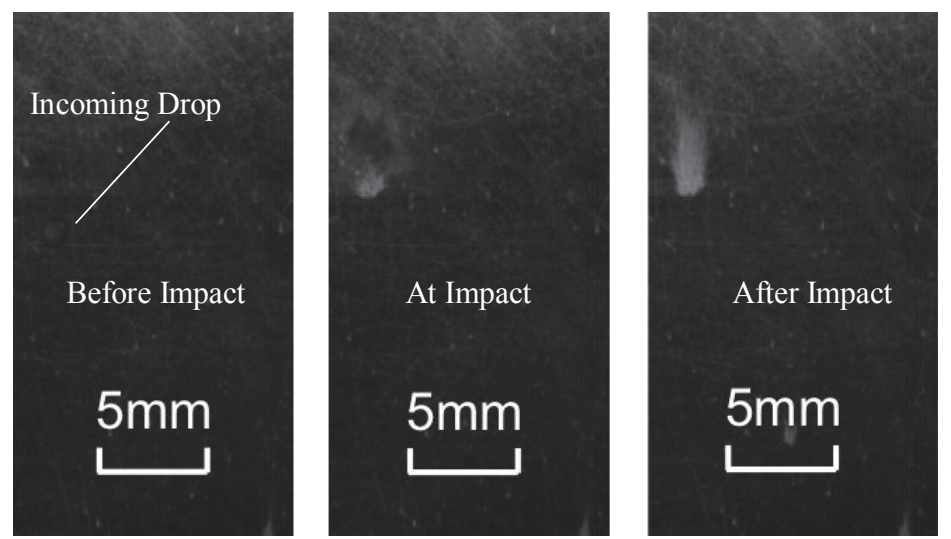

Figure 10. $60^{\circ}$ wedge frozen drop impact frames and ice accumulation (Front view).

\section{Ice Accretion Correlation for Partially Melted Droplets}

To partially melt the droplets, an oxygen /acetylene cross-flow flame was used. The flame had a diameter of 1.2 $\mathrm{cm}$. Based on work performed by Galvery et al., ${ }^{17}$ the flame temperature at the path of the frozen droplet was determined. Galvery et al. quantified the temperature of an oxygen /acetylene mixture flame of non-dimensionalized length. Two locations along the length of the flame were selected for the frozen droplets to travel perpendicular to it. The first set of test points was obtained at the tip of the flame (Test point 1), where the temperature of the flame was measured to be $3,100^{\circ} \mathrm{C}\left(1,760^{\circ} \mathrm{C}\right)$. The second set of test points were obtained for droplets traveling at the $20 \%$ length of the outer envelope of the flame $\left(4,000^{\circ} \mathrm{F}, 2,204^{\circ} \mathrm{C}\right.$, Test point 2$)$.

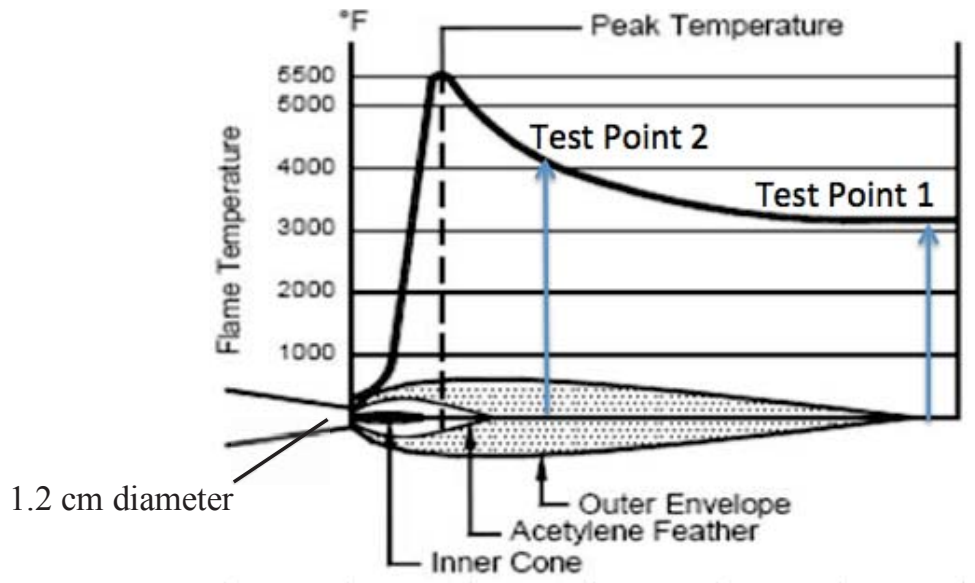

Figure 11. Sideline/oxygen flame temperature from Ref. 17. 
Visualization obtained surrounding $-20^{\circ} \mathrm{C}, 1,704^{\circ} \mathrm{C}$ and $2,200^{\circ} \mathrm{C}$ for impacts at $30^{\circ}$ and $60^{\circ}$ is shown in Figure 12. Standard deviations for each test are presented based on repeat cases. The results indicate that an increase in ice accretion area occurs as the cross-flow input temperature is increased. For the $60^{\circ}$ impact case, the accretion area increased doubles as the temperature is increased from $-20^{\circ} \mathrm{C}$ to $2,200^{\circ} \mathrm{C}$. Similar ice accretion area increases are recorded for the $30^{\circ}$ impact cases.

A sample of the raw images obtained for $30^{\circ}$ and $60^{\circ}$ particle impacts with and without cross-flow heating is shown in Figure 13. The partial melting introduced by the heated cross-flow increases the ice accretion area. This is true despite the effects of additional heat on the surface temperature of the wedge. Notice that the surface temperature of the wedge shown in Table 1 reaches positive values when the oxygen /acetylene flame was used to partially melt the drops. Despite the increase surface temperature of the wedge, ice accretion was recorded at temperatures of $8.79^{\circ} \mathrm{C}$ with water droplets that were partially melted. These experimental results further demonstrate the possibility of ice accretion to warm surfaces of the engine when partially melted water is present.

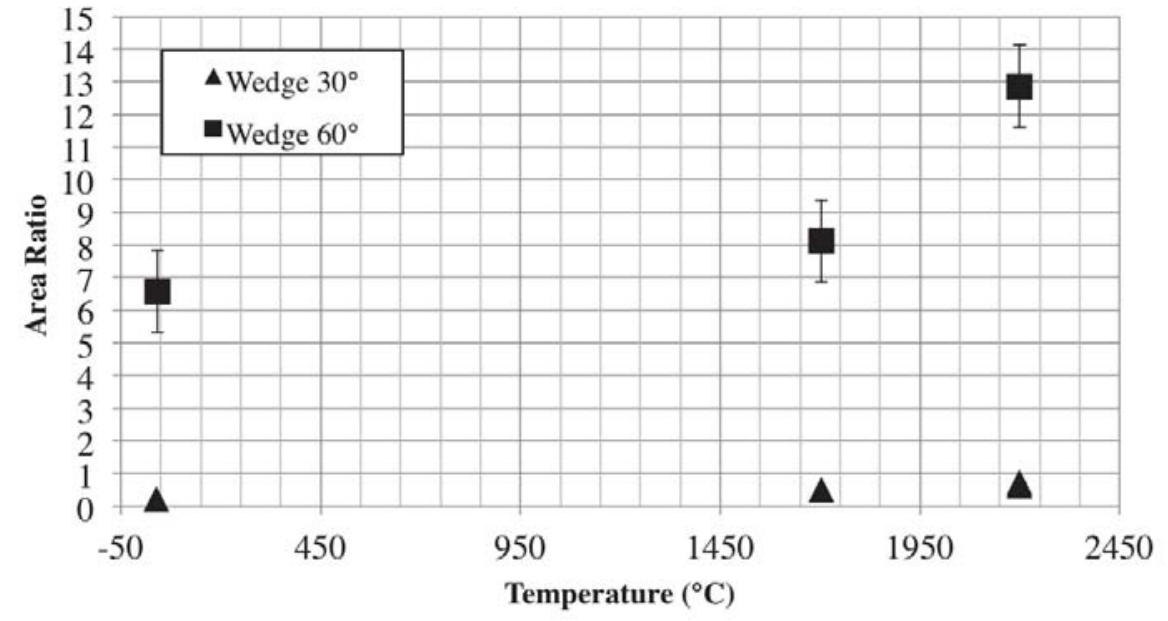

Figure 12. Ice accretion area ratio for varying wedge angles and impact velocities.
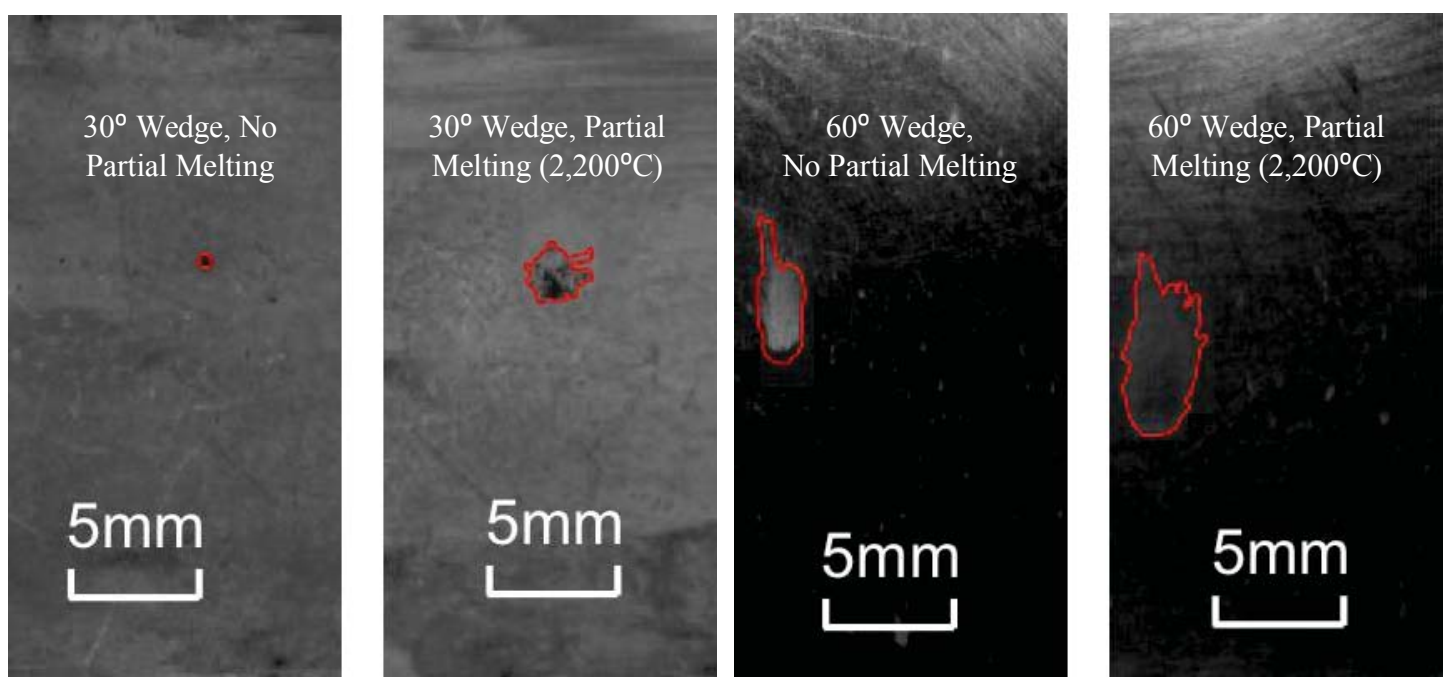

Figure 13. Sample of ice accretion areas for varying wedge angles and partial melting.

Temperature inputs to promote ice droplet partial melting is not the ideal parameter for implementation to ice crystal-modeling efforts. Energy inputs are desired inputs to future ice crystal ice accretion models to be used to quantify partial melting of ice crystals. The energy input for the different cross-flow heating tests presented in this paper were estimated from heat transfer computational models of the frozen droplet exposed to high cross-flow temperatures. The droplet was modeled as fully frozen $\left(-20^{\circ} \mathrm{C}\right)$, and transient analysis was conducted for the calculated residence time of the droplet at the high temperature condition. The residence time was approximated 
based on the flame size and temperature, as well as the traveling velocity of the particle. The residence time of the droplets traveling across the flame at average velocities of $250 \mathrm{~m} / \mathrm{sec}$ was approximated to be $50 \mu \mathrm{sec}$.

A schematic of the droplet and Computational Fluid Dynamics (CFD) domain is depicted in Figure 14. CFD analysis was used to determine the temperature of the frozen droplet when exposed to the estimated temperatures of the flame for the calculated residence times. The energy of input to the droplet can also be calculated from the analysis. A sample of CFD results for a residence time of $50 \mu \mathrm{sec}$ and a cross-flow of 2,200 ${ }^{\circ} \mathrm{C}$ for a $0.65 \mathrm{~mm}$ droplet at an initial temperature of $-20^{\circ} \mathrm{C}$ is shown in Figure 15. Notice that on this image, the scaling legends are set lower than the maximum temperature reached at the surface of the droplet such that the temperature variation inside the droplet can be shown. The maximum surface temperature of the droplet and its average temperature values are plotted on Figure 16. Notice that according to the predictions, the majority of the droplet remains below freezing as shown by the average temperature of the drop, but parts of the surface of the drop reach temperatures that could exceed $40^{\circ} \mathrm{C}$. Also notice that the average temperature for both the $2,200^{\circ} \mathrm{C}$ and the $1,704^{\circ} \mathrm{C}$ cases is similar. The CFD analysis is used to calculate the energy input to the droplet. The accretion area ratio is plotted against the input energies is shown in Figure 17. The ice accretion area ratio dependant on energy mimics the trends of ice accretion area vs. temperature, since the residence time is the same for each case.

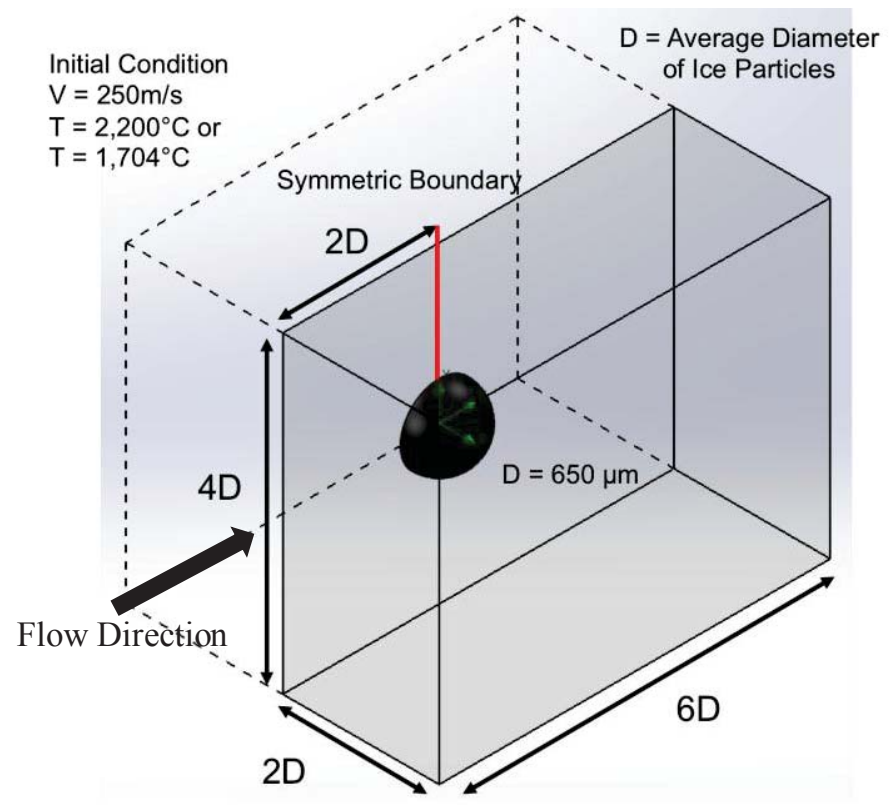

Figure 14. Schematic of frozen drop and CFD computational domain used for energy input calculation.

Two types of energy are needed to fully melt an ice particle. Thermal energy heats the particles to a melting state, while latent heat is required to convert ice into liquid. The total energy required to fully melt an ice particle is defined by Equation 2. The calculated energy input to the frozen droplet traveling at $250 \mathrm{~m} / \mathrm{sec}$ when exposed to across-flow of $2,200^{\circ} \mathrm{C}$ is given by Equation 3 .

$$
\begin{aligned}
E_{\text {full }} & =\rho V_{\text {ice }} c_{p}\left(T_{0}-T_{i c e}\right)+L \rho V_{i c e} \\
\Delta E & =\iiint \rho c_{p} \Delta T d V_{i c e}=\rho c_{p} \overline{\Delta T} V_{i c e}
\end{aligned}
$$

where $L$ is the latent heat of the ice, $\rho$ is the density of the ice, $\Delta T$ is the increase in temperature, being $T_{o}$ the initial temperature of the ice and $T_{i c e}$ the calculated temperature after exposure to thermal energy, and $C_{p}$ is the specific heat capacity of ice. 


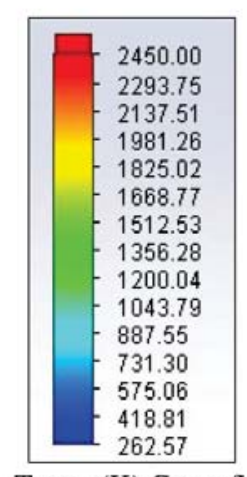

Temp. (K) Cross-flow

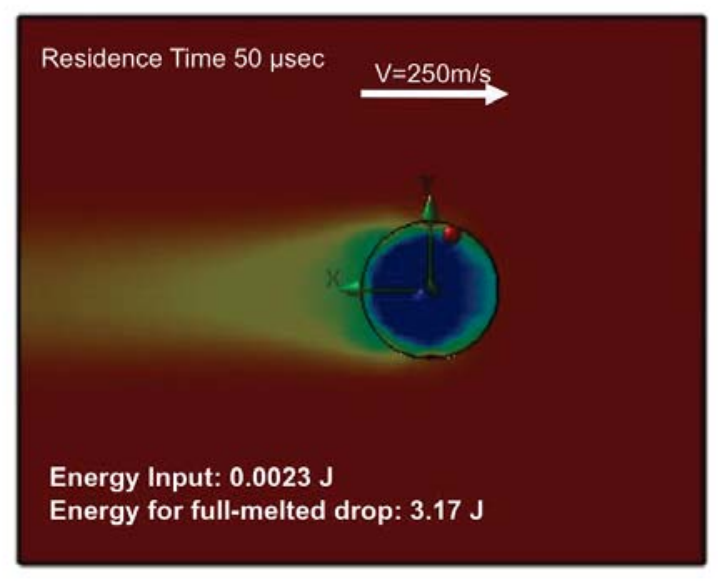

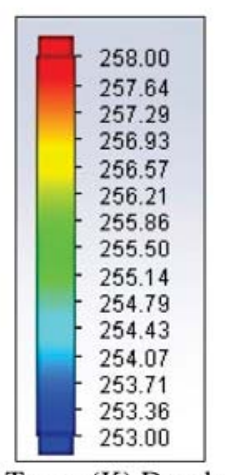

Temp. (K) Droplet

Figure 15. CFD frozen droplet temperature increase calculation for a $100 \mu \mathrm{sec}$ residence time and a cross-flow of $2,200^{\circ} \mathrm{C}$.

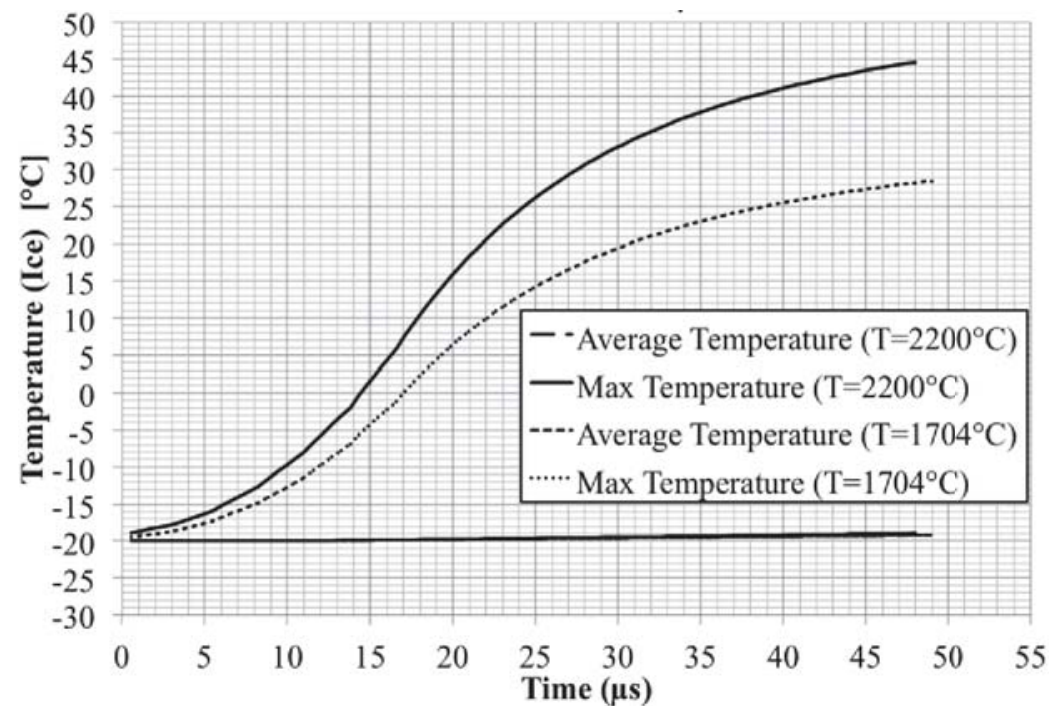

Figure 16. CFD frozen droplet temperature increase calculation for a $100 \mu \mathrm{sec}$ residence time and a cross-flow of $2,200^{\circ} \mathrm{C}$.

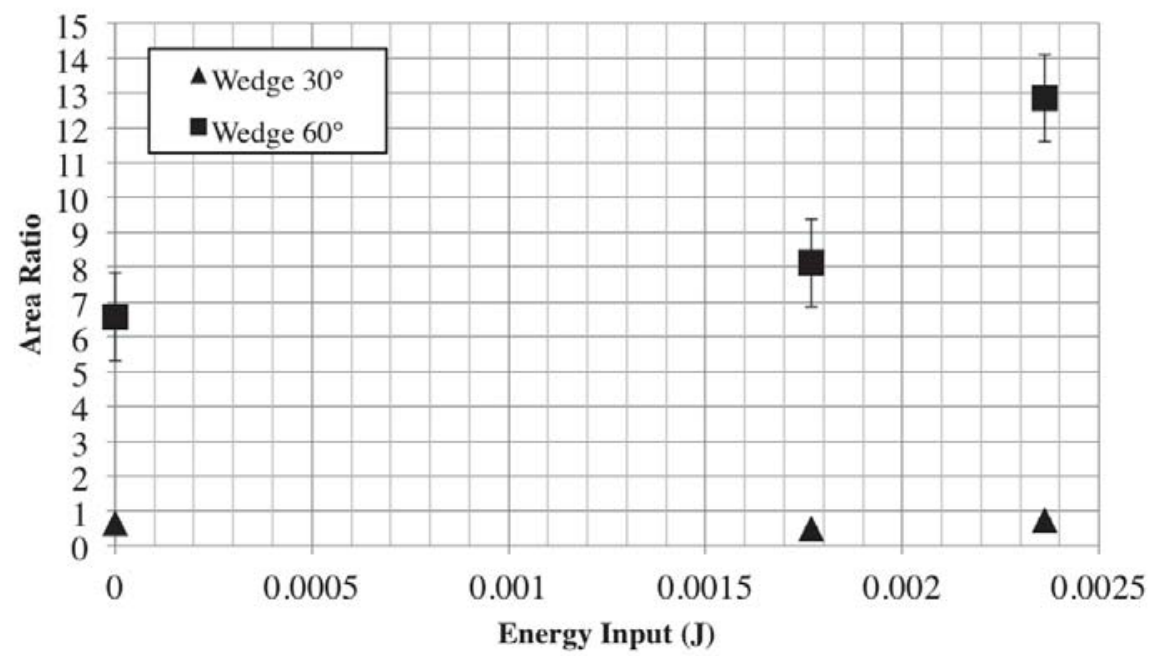

Figure 17. Ice accretion area ratio for varying input energies $(259 \mathrm{~m} / \mathrm{sec}$ droplet velocity). 


\section{Conclusion}

A technique to measure ice accretion of a single partially melted water droplet has been presented. The technique allows for the launching of frozen water droplets ranging from $0.4 \mathrm{~mm}$ to $0.95 \mathrm{~mm}$ diameter at velocities between $140 \mathrm{~m} / \mathrm{sec}$ and $309 \mathrm{~m} / \mathrm{sec}$. The freezing of the water droplets was accomplished by momentary submersion of the drops in liquid nitrogen, while the partial melting was done by introducing a cross-flow oxygen /acetylene flame on the path of the traveling frozen drop. High-speed cameras were used to record the droplet impact and ice accretion left on the impacting surface for varying impact conditions (velocity, partial melting, and impact angle).

From the results presented in this paper, the following conclusions are made:

1) Ice formation of fully frozen particles has been recorded for averaged velocities ranging from $161 \mathrm{~m} / \mathrm{sec}$ to $257 \mathrm{~m} / \mathrm{sec}$ and impact angles of 30,45 and $60^{\circ}$.

2) High-speed visualization perpendicular to the impact surface is suitable for the quantification of ice accretion surface, and impact fracture dynamic analysis. Side view high-speed images are required for particle size traveling velocity calculations.

3) There is a positive linear relationship between impact angle and ice accretion for impact angles between 30 and $60^{\circ}$. The accreted ice area is 1.9 times larger when increasing the impact angle from 45 to $60^{\circ}$ at an impact velocity of $259 \mathrm{~m} / \mathrm{sec}$..

4) The positive slope of the linear relationship between accreted ice area and impact angle also increases with velocity. An increase of $60 \%$ in velocity from $161 \mathrm{~m} / \mathrm{sec}$ to $257 \mathrm{~m} / \mathrm{sec}$ provided an increase on ice accretion area of $96 \%$ at an impact angle of $60^{\circ}$.

5) Partial melting further increases ice accretion of frozen droplets, since additional melted water freezes upon impact to the surface. An estimated input energy of 0.0023 Joules to a frozen droplet traveling at an average speed of $259 \mathrm{~m} / \mathrm{sec}$ doubled the ice accretion area for impact angles of 30 and $60^{\circ}$.

6) It was experimentally demonstrated that ice formation on warm, above freezing, surfaces $\left(8.79^{\circ} \mathrm{C}\right)$ is possible when partially melted droplets impact.

\section{Acknowledgments}

This project was funded by NASA Research Grant and Cooperative Agreement Number NNX12AK16A. The authors would like to acknowledge our valuable interaction with NASA Glenn Research Center engineers. Any opinions, findings, and conclusions or recommendations expressed in this material are those of the author(s) and do not necessarily References.

1. Mason, J., Strapp, W., Chow, P., “The Ice Particle Threat to Engines in Flight," AIAA 2006-206, 44 ${ }^{\text {th }}$ AIAA Aerospace Sciences Meeting and Exhibit, Reno, NV, 9 - 12 January 2006.

2. Struck, P., Lynch, C., "Ice Growth Measurements from Image Data to Support Ice-Crystal and MixedPhase Accretion Testing," AIAA 2012-3036, $4^{\text {th }}$ AIAA Atmospheric and Space Environments Conference, New Orleans, LA., 25 - 28 June, 2012.

3. Struck, P., Tsao, J., Fuleki, D., Knezevici, D., "Preparation for Scaling Studies of Ice-Crystal Icing at the NRC Research Altitude Test Facility," AIAA 2013-2675.

4. Struck, P., Currie, T., Wright, W., Knezevici, D., Fuleki, D., Broeren, A., Vargas, M., Tsao, J., "Fundamental Ice Crystal Accretion Physics Studies," SAE 2011 International Conference on Aircraft and Engine Icing and Ground Deicing, 2011-38-0018, 2011.

5. Currie, T. C., Struk, P. M., Tsao, J., Fuleki, D., and Knezevici, D. C. "Fundamental Study of Mixed-Phase Icing with Application to Ice Crystal Accretion in Aircraft Jet Engines," 4th Atmospheric and Space Environments Conference, AIAA 20123035, 2012.

6. Currie, T., Fuleki, D., Knezevici, D., McLeod, J., "Altitude Scaling of Ice Crystal Accretion,” AIAA 20132677, $5^{\text {th }}$ AIAA Atmospheric and Space Environments Conference, June 24-25, San Diego, CA, 2013.

7. Mason, J., Chow, P., Fuleki, D., "Understanding Ice Crystal Accretion and Shedding Phenomenon in Jet Engines Using a Rig Test," Journal of Engineering for Gas Turbine and Power, Vol. 133, April, 2011.

8. Dezitter, F., Grandin, A., Brenguier, J., Hervy, F., Schlager, H., Villedieu, P., Zalamansky, G., "HAIC (High Altitude Ice Crystals)," AIAA 2013-2674, $5^{\text {th }}$ AIAA Atmospheric and Space Environments Conference, June 24-25, San Diego, CA, 2013. 
9. Writght, W., Jorgenson, P., Veres, J., "Mixed Phase Modeling in GlennICE with Application to Engine Icing," AIAA 2010-7674, AIAA Atmospheric and Space Environments Conference, 2 - 5, Toronto, Ontario Canada, August 2010.

10. Veres, J., Jorgenson, C., "Modeling Commercial Turbofan Engine Icing Risk with Ice Crystal Ingestion," AIAA 2013-2679, 5th AIAA Atmospheric and Space Environments Conference, June 24-25, San Diego, CA, 2013.

11. Guégan, P., Othman, R., Lebreton, D., Pasco, F., Villedieu, P., Meyssonnier, J., Wintenberger, S., "Experimental Investigation of the Kinematics of Post-impact Ice Fragments," International Journal of Impact Engineering, Vol 38, 2011, pp. 786 - 795.

12. Cheong, Y., Salman, A., Hounslow, J., "Effect of impact angle and velocity on the fragment size distribution of glass spheres", Powder Technology, Vol. 138, 2003.

13. Arakawa, M., Maeno, N., Higa, M., Iuima, Y., and Kato, M., “Ejection Velocity of Ice Impact Fragments”, Icarus, Vol. 118, 1995, $341-354$

14. Samimi, A., Moreno, R., Ghadiri, M., "Analysis of impact damage of agglomerates: effect of impact angle," owder Technology, v 143-144, p 97-109, June 25, 2004

15. Knezevici, D., Fuleki, D., Currie, T., and MacLeod, J., "Particle Size Effects on Ice Crystal Accretion", AIAA 2012-3039, $4^{\text {th }}$ AIAA Atmospheric and Space Environments Conference, June 25-28, New Orleans, LA, 2012.

16. Knezevici, D., Fuleki, D., Currie, T., Galeote, B., Chalmers, J., and MacLeod, J., "Particle Size Effects on Ice Crystal Accretion - Part II", AIAA 2013-2676, $5^{\text {th }}$ AIAA Atmospheric and Space Environments Conference, June 24-25, San Diego, CA, 2013.

17. Ref: William L. Galvery Jr., Frank B. Marlow, Welding Essentials, Industrial Press, Inc.; 2 edition (January 15, 2007). 